\title{
Electrochemical Impedance Spectroscopy of Ni-B Coatings and Optimization by Taguchi Method and Grey Relational Analysis
}

\author{
Suman K. Das and Prasanta Sahoo* \\ ${ }^{1}$ Department of Mechanical Engineering, Jadavpur University, Kolkata 700032, India
}

Received 27 December 2010; accepted 13 May 2011

\begin{abstract}
Electroless nickel coatings possess several advantages over electroplating such as ability to coat any material and with uniform thickness. Besides, these coatings are used mainly for their wear resistance and corrosion resistance applications. The present study addresses the corrosion behavior of the coating based on electrical impedance spectroscopy. The effect of the four parameters viz. bath temperature, reducing agent concentration, nickel source concentration and annealing temperature, on the electrochemical characteristics (charge transfer resistance and double layer capacitance) are studied with the help of Taguchi method and grey relational analysis. It is found that the bath temperature has the most significant influence on the corrosion behavior of the coating followed by nickel source concentration. The microstructural characterization of the coating is done with the help of scanning electron microscope, X-ray diffraction analysis and energy dispersive X-ray analysis.
\end{abstract}

Keywords: Electroless, Ni-B, corrosion, EIS, Taguchi, Grey analysis.

\section{Introduction}

Electroless nickel coatings have received wide spread acceptance as an environment friendly alternative of the conventional electroplating. Their properties, especially hardness, wear resistance and corrosion resistance $[1,2]$ have led to their application in industries like aerospace and automotive. Moreover, their ability to coat any material and with uniform thickness has a positive impact on their acceptance. Hypophosphite reduced Ni-P coating [3-5] has already been widely accepted and the quest for achieving a superior hard and wear resistant surface has brought Ni-B coatings at the focus of research [6-12].

\footnotetext{
* Corresponding author. E-mail address: psjume@gmail.com
} 
Ni-B coatings are found to be harder than Ni-P ones in as deposited phase [6]. With heat treatment, the hardness of Ni-B coating is found to increase even more $[6,7]$. The increase of hardness of Ni-B coating with heat treatment is generally attributed to the modification of deposit structure allowing the precipitation of $\mathrm{Ni}-\mathrm{B}$ phases according to the Ni-B phase diagram [8]. With hardness, comes the ability to withstand wear and tear and $\mathrm{Ni}-\mathrm{B}$ acquires high wear resistance particularly after heat treatment [6,9]. Narayanan et al. [6] have developed a dual layer coating of $\mathrm{Ni}-\mathrm{P}$ and $\mathrm{Ni}-\mathrm{B}$ which is found to give even more hardness compared to the individual coatings.

Corrosion can be considered as a deteriorating phenomenon of materials, particularly metals, that often dictates the life of a product. By careful monitoring and devising newer methods to inhibit corrosion, device life could be improved preventing loss to the society. Previous electrochemical studies used to quantify corrosion by measuring the loss of weight suffered by a material exposed to the corrosive environment. This is one of the easiest methods of evaluating the corrosion performance without the use of any sophisticated instrumentation and using the least of the resources. But with the development of technology, and sophisticated instruments being available, more precise investigations of the corrosion behavior of a material are now possible. Present generation studies of the corrosion behavior of electroless nickel coating are mainly conducted through electrochemical tests viz. electrochemical impedance spectroscopy and potentiodynamic polarization studies. The resistance of the coatings towards corrosion is evaluated on the basis of the corrosion parameters obtained from these studies viz. open circuit potential, corrosion current density, charge transfer resistance, double layer capacitance, corrosion rate, etc. [9-11]. Moreover, these electrochemical tests give an idea of the mechanistic pathway of corrosion. Electroless nickel coatings are widely used for corrosion protection application in a variety of environments. They act as barrier coatings, protecting the substrate by sealing it off from the corrosive environments, rather than by sacrificial action. The corrosion resistance of electroless Ni-P coatings is very much dependent on the phosphorous content of the coating. Electroless Ni-high $\mathrm{P}$ coating is effective in offering an excellent protection, whereas electroless $\mathrm{Ni}-$ low $\mathrm{P}$ and $\mathrm{Ni}$-medium $\mathrm{P}$ coatings are not recommended for severe environments [5]. The high corrosion resistance of electroless $\mathrm{Ni}-\mathrm{P}$ coatings may be attributed to the preferential dissolution of nickel that occurs even at the open circuit potential, leading to the enrichment of phosphorus on the surface layer. The enriched phosphorus surface reacts with water to form a layer of adsorbed hypophosphite anions. This layer in turn will block the supply of water to the electrode surface, thereby preventing the hydration of nickel, which is considered to be the first step to form either soluble $\mathrm{Ni}^{2+}$ species or a passive nickel film. Bigdeli and Allahkaram [5] even found the corrosion resistance of Ni-P-SiC coating better than that of plain Ni-P coating. This effect they ascribed to a reduction in the effective metallic area available for corrosion in $\mathrm{Ni}-\mathrm{P}$-nano $\mathrm{SiC}$ coating. They also observed that heat-treatment at $400{ }^{\circ} \mathrm{C}$ for $1 \mathrm{~h}$ significantly improved the coating density and structure, giving rise to an enhanced corrosion resistance for the applied EN and EN composite coatings. 
Electroless Ni-B coatings are found to have a lower resistance against corrosion compared to Ni-P coatings [10,13]. The difference in corrosion resistance between electroless $\mathrm{Ni}-\mathrm{P}$ and $\mathrm{Ni}-\mathrm{B}$ coatings is mainly due to the difference in their structure. It is believed that the passivation films that form on Ni-B coated surfaces are not as glassy or protective enough as those that form on high phosphorous electroless nickel coatings. The phase boundaries present in Ni-B deposits might also be responsible for causing discontinuity of the passivation film, which are the preferred sites for the initiation of corrosion process. Besides, the inhomogeneous distribution of boron and thallium throughout the coating provides areas of different corrosion potential on the surface, which would lead to the formation of minute active/passive corrosion cells and accelerated the corrosion attack [10].

However, Ni-B coating is applied to increase the corrosion resistance of steel [14]. Increase in boron content is found to increase the corrosion resistance of Ni-B coatings [12]. Anik et al. [12] noticed that increase of boron content also increased the sensitivity of the film corrosion resistance to the film boron content. This phenomenon they attributed to the effect of complications arising from the local cells formed by the deposited thallium on the corrosion resistance decreases as the boron content of the film increases.

Heat treatment is found to decrease the corrosion resistance of electroless coatings invariably $[10,12]$. This is attributed to the change of microstructure of the coatings with heat treatment. Electroless coatings in as deposited condition generally exhibit an amorphous structure which imparts higher corrosion resistance. But, heat treatment induces crystallinity into the deposits, which in turn increases the grain boundaries that form active sites for corrosion attack $[9,10]$. The corrosion resistance of electroless $\mathrm{Ni}-\mathrm{P}$ and $\mathrm{Ni}-\mathrm{B}$ deposits is found to increase with the incorporation of an additional alloying element such as $\mathrm{Cu}$, $\mathrm{Zn}, \mathrm{W}$, Mo, etc., or with the incorporation of second phase particles, such as silicon nitride, ceria and titania, in the metal matrix [6]. Also, the presence of sodium hypophosphite in $\mathrm{Ni}-\mathrm{B}$ bath enhances the corrosion resistance of $\mathrm{Ni}-\mathrm{B}$ by forming Ni-B-P [9]. The concept of Ni-P/Ni-B duplex coatings was found to have a noblest electrochemical performance than the individual $\mathrm{Ni}-\mathrm{P}$ and $\mathrm{Ni}-\mathrm{B}$ coatings $[6,7]$. The Nyquist plots obtained for electroless $\mathrm{Ni}-\mathrm{P}, \mathrm{Ni}-\mathrm{B}$ and, $\mathrm{Ni}-$ $\mathrm{P} / \mathrm{Ni}-\mathrm{B}$ and $\mathrm{Ni}-\mathrm{B} / \mathrm{Ni}-\mathrm{P}$ duplex coatings, both in as-plated and heat-treated conditions, at their respective open circuit potentials, in $3.5 \%$ sodium chloride solution, exhibit a single semicircle in the high frequency region. However, these curves differ considerably in their size. This indicates that the same fundamental process is occurring on all these coatings but over a different effective area in each case [6].

As the corrosion resistance of $\mathrm{Ni}-\mathrm{B}$ coating is lesser than $\mathrm{Ni}-\mathrm{P}$ coating, an extensive study regarding the corrosion behavior of the former has remained neglected. But Ni-B coatings are often preferred in various tribological applications due to their superior hardness and wear resistance compared to Ni-P coatings. Hence, a systematic study of the electrochemical behavior of Ni-B coatings is necessary as the coatings in various applications would definitely encounter corrosion. The present study tries to address this need. Here, the effect 
of coating parameters (bath temperature, reducing agent concentration and nickel source concentration) and annealing temperature on the corrosion behavior of electroless Ni-B coatings is studied with the help of electrochemical impedance spectroscopy (EIS).

The EIS technique has proven to be a valuable test method for the electrochemical characterization of the protective coating on metals. This method provides very detailed data on the effectiveness of a coating over a relatively small area. The EIS technique can indicate the presence and rate of corrosion, and the moisture content of the coating prior to corrosion [13]. Thus, the EIS technique is chosen to characterize the corrosion behavior of the coatings in the present study.

Taguchi method, in conjunction with Grey relational analysis is employed to optimize the process parameters in order to enhance the corrosion resistant properties of electroless Ni-B coating. A confirmation experiment is conducted to verify the optimal process parameter combination as predicted by Taguchi analysis. Analysis of variance is also carried out to observe the level of significance of the factors and their interactions. The surface morphology and composition of Ni-B coatings are studied with the help of scanning electron microscopy, energy dispersed X-ray analysis and X-ray diffraction analysis. The present work is a fresh attempt to optimize the coating deposition parameters in order to obtain an enhanced corrosion resistance of electroless Ni-B coating. Two corrosion parameters (charge transfer resistance and double layer capacitance) are considered in the optimization in order to better capture the corrosion behaviour of the coating.

\section{Taguchi method}

G. Taguchi introduced the Taguchi technique [15-17] and since then it has been widely used in the engineering domain to get the desired performance characteristics by optimizing the design parameters. In Taguchi technique, threestages such as system design, parameter design, and tolerance design are employed. System design consists of the usage of scientific and engineering information required for producing a part. Tolerance design is employed to determine and to analyze tolerances about the optimum combinations suggested by parameter design. Parameter design is used to obtain the optimum levels of process parameters for developing the quality characteristics and to determine the product parameter values depending on the optimum process parameter values. Based on orthogonal arrays (OA), the number of experiments which may increase the time and cost can be reduced by using Taguchi technique. Now, Taguchi method arrives at optimality by the use of robust parameter design. Robust parameter design is an engineering method for product and process design that focuses on minimizing variation. Hence, to account for the variation within a trial condition, Taguchi uses signal to noise $(\mathrm{S} / \mathrm{N})$ ratio to measure the performance of the process response. $\mathrm{S} / \mathrm{N}$ ratio being the ratio of mean to standard deviation can effectively consider the variation encountered in a set of trials. Moreover, based on the objective of the experiment, $\mathrm{S} / \mathrm{N}$ ratio 
characteristics can be divided on the basis of three criteria: lower-the-better (LB), higher-the better (HB) and nominal-the best (NB). The parameter level combination that maximizes the appropriate $\mathrm{S} / \mathrm{N}$ ratio is the optimal setting.

\section{Grey relational analysis}

In the present problem, the electrochemical characteristics are evaluated with the help of EIS analysis form which two parameters are considered viz. charge transfer resistance and double layer capacitance. Hence, it becomes a multiple response problem of optimization. In a system, that is complex and multivariate, the relationship between various factors is unclear. Such systems are often "grey" implying poor, incomplete, and uncertain information. Their analysis by classical statistical procedures may not be acceptable without large data sets and data satisfying certain mathematical criteria. The grey theory [18], on the contrary, makes use of relatively small data sets and does not demand strict compliance to certain statistical laws, simple or linear relationships among the observables. So, it is suitable to apply grey relational theory to the present multi-response optimization. The optimization of the process is performed in the following steps:

(a) Performing the grey relational generation in which the results of the experiments are normalized in the range between 0 and 1 .

(b) Calculation of the grey relational coefficients from the normalized data to represent the correlation between the desired and actual experimental data.

(c) Calculating the grey relational grade by averaging the grey relational coefficients. The grey relational grade is treated as the overall response of the process instead of the multiple responses of friction and wear.

(d) Performing statistical analysis of variance (ANOVA) for the input parameters with the grey relational grade and find which parameter significantly affects the process performance.

(e) Selecting the optimal levels of process parameters.

(f) Conducting confirmation experiment and verifying the optimal process parameters setting.

Hence, the grey relational analysis converts the multi-response problem into a single response one which can be effectively fitted into Taguchi orthogonal design for further processing.

\section{Experimental details \\ Materials and methods}

Steel (AISI 1040) blocks of size $20 \mathrm{~mm} \times 20 \mathrm{~mm} \times 8 \mathrm{~mm}$ are used as substrates for the development of electroless $\mathrm{Ni}-\mathrm{B}$ coating. A large number of trials are conducted before deciding on the final range of the Ni-B bath composition. The bath composition together with the operating conditions for successful deposition of electroless Ni-B is shown in Table 1. In the electroless bath, nickel chloride provides the nickel ions, while sodium borohydride acts as the reducing agent, reducing nickel into its elemental form while itself getting oxidized. Since the reaction between nickel chloride and sodium borohydride is quite intense and 
fast, ethylenediamine is used as the complexing agent to slow down this reaction and make the process stable. Ethylenediamine forms metastable complexes with nickel ions and releases them slowly as required in the reaction. Although complexing agent stabilizes the reactions to a great extent, there is always a possibility of solution breakdown due to the formation of nickel borides and the subsequent chain reaction. Hence a stabilizer is needed so that deposition occurs at a predictable rate and on the substrate surface. In the present bath, lead nitrate plays the role of a stabilizer and prevents solution breakdown during the coating period. The $\mathrm{pH}$ of the solution is maintained around 12.5 by continuous monitoring with a $\mathrm{pH}$ meter. The steps for obtaining the Ni-B deposit are as follows:

- Preparation of the substrate.

- Cleaning of the substrate using acetone.

- Pickling treatment of the substrate in dilute (18\%) hydrochloric acid.

- Activation of the substrate in warm $\left(55^{\circ} \mathrm{C}\right)$ palladium chloride solution.

- Immersion of the substrate in the electroless bath and deposition carried out for $2 \mathrm{~h}$.

- After deposition, the coated samples are taken out and cleaned using distilled water.

- The samples are annealed in a box furnace at different temperatures $\left(250{ }^{\circ} \mathrm{C}\right.$, $350{ }^{\circ} \mathrm{C}, 450{ }^{\circ} \mathrm{C}$ ) according to the OA.

- The annealed samples are air cooled to ambient temperature $\left(28{ }^{\circ} \mathrm{C}\right)$ without any artificial cooling.

Table 1. Bath constituents and their ranges.

\begin{tabular}{|l|c|}
\hline Parameters & Ranges of parameters \\
\hline Nickel chloride & $15-25 \mathrm{~g} / \mathrm{L}$ \\
\hline Sodium borohydride & $0.6-1.0 \mathrm{~g} / \mathrm{L}$ \\
\hline Ethylenediamine & $59 \mathrm{~g} / \mathrm{L}$ \\
\hline Lead nitrate & $0.0145 \mathrm{~g} / \mathrm{L}$ \\
\hline Sodium hydroxide & $40 \mathrm{~g} / \mathrm{L}$ \\
\hline Bath temperature & $85-95^{\circ} \mathrm{C}$ \\
\hline $\mathrm{pH}$ of solution & 12.5 \\
\hline
\end{tabular}

There have been several propositions regarding the reaction mechanism of electroless Ni-B coatings, but one of the mechanisms proposed by Gorbunova et al. [19] is well supported by experimental evidence. The proposed scheme for the reaction mechanism of nickel boron plating consists of mainly three steps:

Reduction of nickel:

$$
\begin{aligned}
& \mathrm{BH}_{4}^{-}+4 \mathrm{H}_{2} \mathrm{O} \rightarrow \mathrm{B}(\mathrm{OH})_{4}^{-}+4 \mathrm{H}+4 \mathrm{H}^{+}+4 \mathrm{e}^{-} \\
& 2 \mathrm{Ni}^{+2}+4 \mathrm{e}^{-} \rightarrow 2 \mathrm{Ni}^{0} \\
& \mathrm{BH}_{4}^{-}+2 \mathrm{Ni}^{+2}+4 \mathrm{H}_{2} \mathrm{O} \rightarrow 2 \mathrm{Ni}^{0}+\mathrm{B}(\mathrm{OH})_{4}^{-}+2 \mathrm{H}_{2}+4 \mathrm{H}^{+}
\end{aligned}
$$


Reduction of boron:

$\mathrm{BH}_{4}^{-}+\mathrm{H}^{+} \rightarrow \mathrm{BH}_{3}+\mathrm{H}_{2} \rightarrow \mathrm{B}+\frac{5}{2} \mathrm{H}_{2}$

Hydrolysis of borohydride:

$\mathrm{BH}_{4}^{-}+4 \mathrm{H}_{2} \mathrm{O} \rightarrow \mathrm{B}(\mathrm{OH})_{4}^{-}+4 \mathrm{H}+4 \mathrm{H}^{+}+4 \mathrm{e}^{-} \rightarrow \mathrm{B}(\mathrm{OH})_{4}^{-}+4 \mathrm{H}_{2}$

It is important to note here that corrosion of Ni-P coatings is found to be dependent on the smoothness of the coating [20], which again depends on the smoothness of the substrate. Such behavior is also suspected in case of Ni-B coatings [14] and hence to remove the effect of substrate roughness on the final response, all the substrates need to be of similar roughness. Thus, large numbers of samples are prepared and after all the processing prior to coating, these are subjected to roughness evaluation (centre line average, $R_{\mathrm{a}}$ ). Only those specimens that show insignificant variation (less than 0.1\%) in roughness are used for coating deposition.

\section{Characterization of the coating}

After the development of the coating, it is necessary to characterize the same so that confirmation can be made about the proper development of the coating. Moreover, macroscopic behavior of the coating can be related to the changes occurring in its microstructure. In the present case, surface morphology of the coating is observed through scanning electron microscope (SEM) (JEOL, JSM 6360) in order to analyze the effect of heat treatment on the microstructure of the deposits. Energy dispersive X-ray analysis (EDAX Corporation) is used to determine the composition of the coating in terms of the weight percentages of nickel and boron. The different precipitated phases both before and after heat treatment are identified with the help of X-ray diffraction (XRD) analysis (Rigaku, Ultima III).

Table 2. Design parameters and their levels.

\begin{tabular}{|c|c|c|c|c|}
\hline \multirow{2}{*}{ Design factors } & \multirow{2}{*}{ Unit } & \multicolumn{3}{|c|}{ Levels } \\
\cline { 3 - 5 } & & 1 & 2 & 3 \\
\hline Bath temperature (A) & ${ }^{\circ} \mathrm{C}$ & 85 & $90^{\mathrm{a}}$ & 95 \\
\hline Reducer concentration $(\mathrm{B})$ & $(\mathrm{g} / \mathrm{L})$ & 0.6 & $0.8^{\mathrm{a}}$ & 1.0 \\
\hline Nickel source concentration $(\mathrm{C})$ & $(\mathrm{g} / \mathrm{L})$ & 15 & $20^{\mathrm{a}}$ & 25 \\
\hline Annealing temperature $(\mathrm{D})$ & ${ }^{\circ} \mathrm{C}$ & 25 & $350^{\mathrm{a}}$ & 450 \\
\hline a: initial condition
\end{tabular}

\section{Choosing design parameters}

It is found that the characteristics of electroless coating get affected by several factors such as bath temperature, reducing agent concentration, nickel source 
concentration, stabilizer concentration, $\mathrm{pH}$ of the solution, substrate, bath load, etc. Consideration of all the factors would make the experimental design highly complex and the analysis even more complicated. A review of the recent literatures revealed that the three factors viz. bath temperature (A), concentration of reducing agent (sodium borohydride) (B) and concentration of nickel source (nickel chloride) (C) are the mostly preferred factors used by the researchers to control the properties of electroless nickel deposits. The bath temperature initiates the reaction mechanism and thereby determines the rate of reaction by controlling the ionization and charge transfer process. Borohydride reduced plating baths are generally operated between $85-95{ }^{\circ} \mathrm{C}$ [1]. Below $85{ }^{\circ} \mathrm{C}$, the plating rate is very slow but the rate increases exponentially with increase in temperature. Above $95^{\circ} \mathrm{C}$ the bath is very much prone to instability. The plating rate is also affected by the concentration of sodium borohydride and it is generally observed that as the borohydride concentration increases, the plating rate increases, but the bath stability decreases. Hence for a stable operation of the plating bath, sodium borohydride concentration is kept between $0.6-1.0 \mathrm{~g} / \mathrm{L}$. Nickel chloride is the source of nickel ions in the bath. Thus these three coating parameters are considered as the main design parameters along with their interactions in the present study. Moreover, annealing is found to have a great effect on the tribological properties of the electroless coatings, but its effect on the corrosion resistance properties of electroless $\mathrm{Ni}-\mathrm{B}$ coatings has remained a debatable issue. Hence, the annealing temperature is taken into account as the fourth parameter in the experimental design. The considered design parameters, together with their levels are shown in Table 2. Consideration of three levels allows the study of non-linear effects if any.

\section{Response variable}

In the present article, corrosion behaviour of electroless Ni-B coatings is studied with the help of electrochemical impedance spectroscopy. Hence, the two popularly evaluated parameters, i.e., charge transfer resistance $\left(R_{\mathrm{ct}}\right)$ and double layer capacitance $\left(C_{\mathrm{dl}}\right)$, are considered as the response variables. A lower value of $R_{\mathrm{ct}}$ and a higher value of $C_{\mathrm{dl}}$ indicate that the material under test has a higher resistance against corrosion.

\section{Design of experiments}

Design of experiments (DOE) is a technique to obtain the maximum amount of conclusive information from the minimum amount of work, time, energy, money, or other limited resource. The DOE using Taguchi approach can economically satisfy the needs of problem solving and product/process design optimization projects in the manufacturing industry. By learning and applying this technique, it is possible to significantly reduce the time required for experimental investigations. As mentioned earlier, Taguchi method uses an OA (orthogonal array) to reduce the number of experiments for determining the optimal process parameters. Orthogonal arrays allow one to compute the main and interaction effects via a minimum number of experimental trials [17]. Several standard OAs have been tabulated by Taguchi. The choice of a suitable OA design is critical for 
the success of an experiment and depends on the total degrees of freedom (dof) required to study the main and interaction effects, the goal of the experiment, resources and budget available and time constraints. Degree of freedom (dof) refers to the number of fair and independent comparisons that can be made from a set of observations. In the context of DOE, the number of degrees of freedom of a particular parameter is one less than the number of levels associated with the parameter. In the present case since each of the main factors is associated with three levels, the dof of each of the factors is two. Again, the number of dofs associated with an interaction is the product of the number of dof associated with each main effect involved in the interaction. In the present case each interaction is associated with four dofs $(2 \times 2)$. Therefore the total dof for a three level design with four main parameters and three interactions is equal to twenty $(4 \times 2+3 \times 4)$.

Table 3. $L_{27}$ orthogonal array with main parameters and interactions.

\begin{tabular}{|c|c|c|c|c|c|c|c|c|c|c|c|c|c|}
\hline & \multicolumn{13}{|c|}{ Column numbers } \\
\hline Trial & 1 & 2 & 3 & 4 & 5 & 6 & 7 & 8 & 9 & 10 & 11 & 12 & 13 \\
\hline No. & A & B & $A \times B$ & $A \times B$ & $\mathrm{C}$ & $\mathrm{A} \times \mathrm{C}$ & $\mathrm{A} \times \mathrm{C}$ & $\mathrm{B} \times \mathrm{C}$ & $\mathrm{D}$ & - & $\mathrm{B} \times \mathrm{C}$ & - & - \\
\hline 1 & 1 & 1 & 1 & 1 & 1 & 1 & 1 & 1 & 1 & 1 & 1 & 1 & 1 \\
\hline 2 & 1 & 1 & 1 & 1 & 2 & 2 & 2 & 2 & 2 & 2 & 2 & 2 & 2 \\
\hline 3 & 1 & 1 & 1 & 1 & 3 & 3 & 3 & 3 & 3 & 3 & 3 & 3 & 3 \\
\hline 4 & 1 & 2 & 2 & 2 & 1 & 1 & 1 & 2 & 2 & 2 & 3 & 3 & 3 \\
\hline 5 & 1 & 2 & 2 & 2 & 2 & 2 & 2 & 3 & 3 & 3 & 1 & 1 & 1 \\
\hline 6 & 1 & 2 & 2 & 2 & 3 & 3 & 3 & 1 & 1 & 1 & 2 & 2 & 2 \\
\hline 7 & 1 & 3 & 3 & 3 & 1 & 1 & 1 & 3 & 3 & 3 & 2 & 2 & 2 \\
\hline 8 & 1 & 3 & 3 & 3 & 2 & 2 & 2 & 1 & 1 & 1 & 3 & 3 & 3 \\
\hline 9 & 1 & 3 & 3 & 3 & 3 & 3 & 3 & 2 & 2 & 2 & 1 & 1 & 1 \\
\hline 10 & 2 & 1 & 2 & 3 & 1 & 2 & 3 & 1 & 2 & 3 & 1 & 2 & 3 \\
\hline 11 & 2 & 1 & 2 & 3 & 2 & 3 & 1 & 2 & 3 & 1 & 2 & 3 & 1 \\
\hline 12 & 2 & 1 & 2 & 3 & 3 & 1 & 2 & 3 & 1 & 2 & 3 & 1 & 2 \\
\hline 13 & 2 & 2 & 3 & 1 & 1 & 2 & 3 & 2 & 3 & 1 & 3 & 1 & 2 \\
\hline 14 & 2 & 2 & 3 & 1 & 2 & 3 & 1 & 3 & 1 & 2 & 1 & 2 & 3 \\
\hline 15 & 2 & 2 & 3 & 1 & 3 & 1 & 2 & 1 & 2 & 3 & 2 & 3 & 1 \\
\hline 16 & 2 & 3 & 1 & 2 & 1 & 2 & 3 & 3 & 1 & 2 & 2 & 3 & 1 \\
\hline 17 & 2 & 3 & 1 & 2 & 2 & 3 & 1 & 1 & 2 & 3 & 3 & 1 & 2 \\
\hline 18 & 2 & 3 & 1 & 2 & 3 & 1 & 2 & 2 & 3 & 1 & 1 & 2 & 3 \\
\hline 19 & 3 & 1 & 3 & 2 & 1 & 3 & 2 & 1 & 3 & 2 & 1 & 3 & 2 \\
\hline 20 & 3 & 1 & 3 & 2 & 2 & 1 & 3 & 2 & 1 & 3 & 2 & 1 & 3 \\
\hline 21 & 3 & 1 & 3 & 2 & 3 & 2 & 1 & 3 & 2 & 1 & 3 & 2 & 1 \\
\hline 22 & 3 & 2 & 1 & 3 & 1 & 3 & 2 & 2 & 1 & 3 & 3 & 2 & 1 \\
\hline 23 & 3 & 2 & 1 & 3 & 2 & 1 & 3 & 3 & 2 & 1 & 1 & 3 & 2 \\
\hline 24 & 3 & 2 & 1 & 3 & 3 & 2 & 1 & 1 & 3 & 2 & 2 & 1 & 3 \\
\hline 25 & 3 & 3 & 2 & 1 & 1 & 3 & 2 & 3 & 2 & 1 & 2 & 1 & 3 \\
\hline 26 & 3 & 3 & 2 & 1 & 2 & 1 & 3 & 1 & 3 & 2 & 3 & 2 & 1 \\
\hline 27 & 3 & 3 & 2 & 1 & 3 & 2 & 1 & 2 & 1 & 3 & 1 & 3 & 2 \\
\hline
\end{tabular}

It is important to notice that the number of experimental trials in the OA must be greater than the total dof required for studying the effects. Hence, $L_{27} \mathrm{OA}$, 
requiring twenty seven experimental runs is suitably chosen for the present case. The assignment of the factors and interactions to the columns of the array is done on the basis of the Triangular Table for 3-level OA [15] as suggested by Taguchi. The $L_{27}$ OA together with the column assignments are shown in Table 3 . The values in each cell of the main parameter columns (A, B, C and D) in the array indicate their levels (1, 2 and 3). Again in case of interactions, two columns are assigned to a single interaction and the two cell values in a particular row indicate the levels of each of the factors involved in the interaction. The unassigned columns in the OA are kept for the error terms.

\section{Electrochemical tests}

The EIS tests are performed with a potentiostat (Gill AC) of ACM Instruments, UK. A $3.5 \%$ sodium chloride solution is taken as the electrolyte and the tests are conducted at a constant ambient temperature of about $25^{\circ} \mathrm{C}$. The electrochemical cell consists of three electrodes. The coated specimen forms the working electrode which is actually the sample being interrogated. A saturated calomel electrode (SCE) forms the reference electrode, which provides a stable "reference" against which the applied potential may be accurately measured. A platinum electrode serves as the counter electrode, which provides the path for the applied current into the solution. The design of the cell is such that only an area of $1 \mathrm{~cm}^{2}$ of the coated surface is exposed to the electrolyte. A settling time of $15 \mathrm{~min}$ is assigned before every experiment in order to stabilize the open circuit potential (OCP). The potentiostat is controlled via a $\mathrm{PC}$ which also captures the EIS data. The applied frequency was varied from $10 \mathrm{KHz}$ to $0.01 \mathrm{~Hz}$ and the Nyquist plots obtained from the tests in general exhibited a single semicircle in the high frequency region which is quite consistent to that observed by Sankara Narayanan et al. [10]. The electrical model that can be used to simulate this type of electrochemical behaviour is given in Fig. 1. The charge transfer resistance $\left(R_{\mathrm{ct}}\right)$ is represented by the resistance of electron transfer during electrochemical reaction course. The double layer capacitance $\left(C_{\mathrm{dl}}\right)$ can be correlated to the delamination of the coating. Solution resistance $\left(R_{\mathrm{S}}\right)$ is referred to the resistance between the work electrode and reference electrode. The values of charge transfer resistance $\left(R_{\mathrm{ct}}\right)$ and double layer capacitance $\left(C_{\mathrm{dl}}\right)$ were determined from the Nyquist plot by fitting a semicircle using the accompanying software.

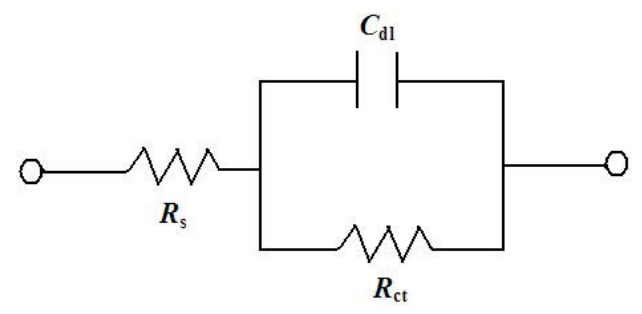

Figure 1. Electrical circuit model to fit EIS data. 


\section{Results and discussion \\ Coating microstructure study}

The SEM micrographs of the coating surfaces in as-deposited and heat treated (at $250{ }^{\circ} \mathrm{C}, 350{ }^{\circ} \mathrm{C}$ and $450{ }^{\circ} \mathrm{C}$ for one hour) conditions are shown in Fig. 2. The surface exhibits a cauliflower like structure which strongly points towards the coating possessing a lubricious behavior [8]. The surface of the Ni-B coatings appears to be dense and matte grey in colour with low porosity. Also by careful observation, it can be noted that the Ni-B nodules are quite deflated and flat in as deposited condition but gradually grow in size with increase in heat treatment temperature giving rise to coarse grained structure.

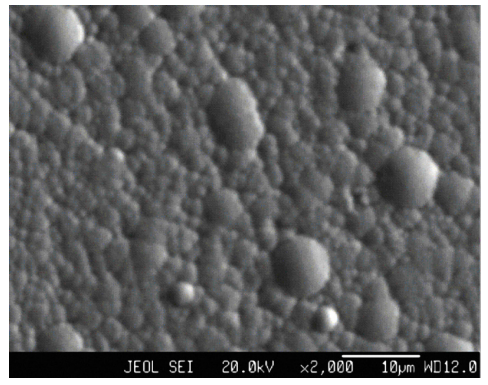

(a)

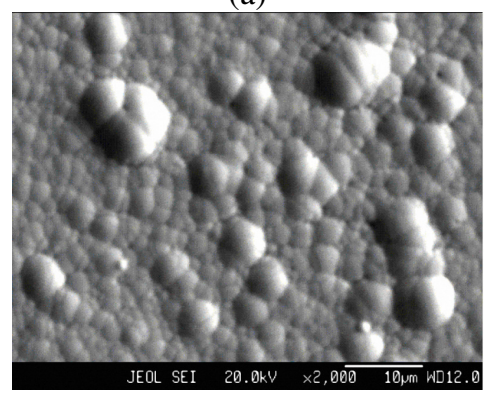

(c)

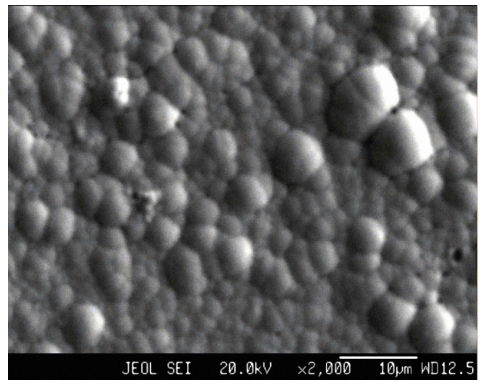

(b)

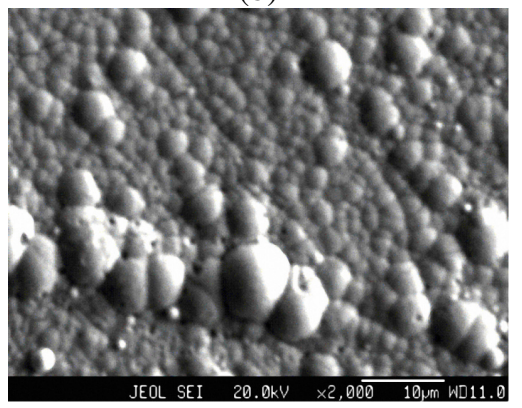

(d)

Figure 2. SEM pictures of the coating surface (a) as deposited, (b) annealed at $250{ }^{\circ} \mathrm{C}$, (c) annealed at $350{ }^{\circ} \mathrm{C}$ and (d) annealed at $450{ }^{\circ} \mathrm{C}$.

Energy dispersive X-ray analysis is performed with one of the latest EDX detectors that do not contain any beryllium window, in order to detect light elements like boron. The Beryllium window if present absorbs all the soft X-rays thereby precluding the detection of lighter elements. The EDX plots are shown in Fig. 3 and boron content in terms of weight percentages is found to be in the range of $5.72-7.46$, while the remaining is mostly nickel. The XRD analysis (Fig. 4) shows that the Ni-B film is almost amorphous in as-deposited phase but turns crystalline with heat treatment. This is evident from the presence of microcrystalline peaks in as-deposited phase whereas broad peaks of $\mathrm{Ni}, \mathrm{Ni}_{2} \mathrm{~B}$ and $\mathrm{Ni}_{3} \mathrm{~B}$ are found in samples heat treated at $350{ }^{\circ} \mathrm{C}$. 


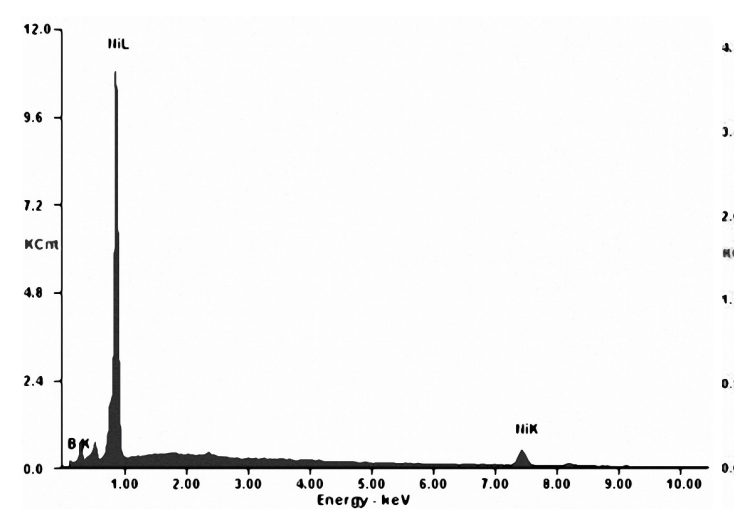

(a)

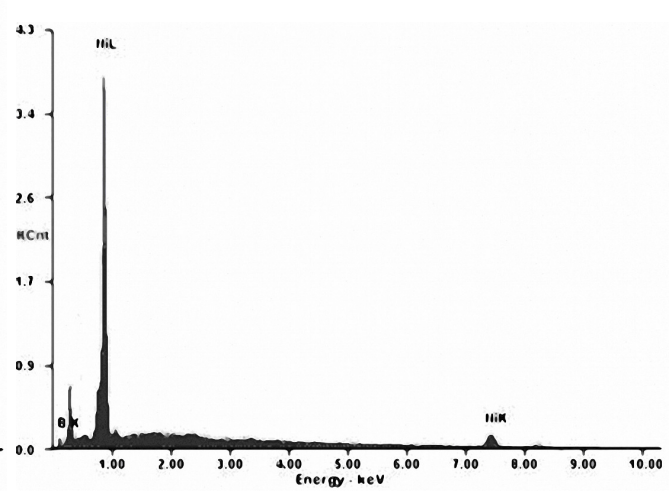

(b)

Figure 3. EDX spectra of Ni-B coatings (a) $0.6 \mathrm{~g} / \mathrm{L} \mathrm{NaBH}_{4}$, (b) $1.0 \mathrm{~g} / \mathrm{L} \mathrm{NaBH}_{4}$.
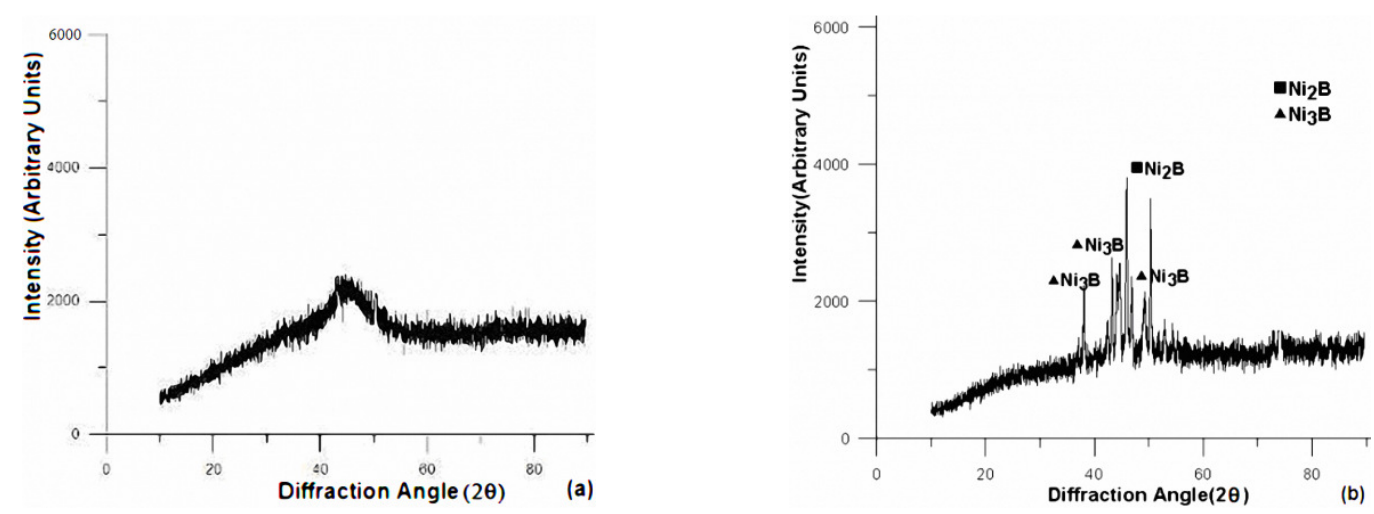

Figure 4. XRD plots of electroless Ni-B coating in (a) as-deposited and (b) heat treated at $350{ }^{\circ} \mathrm{C}$.

Table 4. Experimental results for $R_{\mathrm{ct}}$ and $C_{\mathrm{dl}}$.

\begin{tabular}{|c|c|c|c|c|c|}
\hline $\begin{array}{c}\text { Sl. } \\
\text { No. }\end{array}$ & $\begin{array}{c}R_{\mathrm{ct}} \\
\text { Ohms.cm }\end{array}$ & $\begin{array}{c}C_{\mathrm{dl}} \\
\left(\mathrm{F} \times 10^{-4}\right)\end{array}$ & $\begin{array}{c}\text { Sl. } \\
\text { No. }\end{array}$ & $\begin{array}{c}R_{\mathrm{ct}} \\
\text { Ohms.cm }\end{array}$ & $\begin{array}{c}C_{\mathrm{dl}} \\
\left(\mathrm{F} \times 10^{-4}\right)\end{array}$ \\
\hline 1 & 2222 & 2.4014 & 15 & 3676 & 0.76887 \\
\hline 2 & 2147 & 0.93259 & 16 & 3644 & 0.59317 \\
\hline 3 & 1230 & 4.0584 & 17 & 6738 & 0.68294 \\
\hline 4 & 782.2 & 3.7559 & 18 & 17980 & 0.59893 \\
\hline 5 & 8908 & 0.73026 & 19 & 9962 & 1.5175 \\
\hline 6 & 1114 & 1.3036 & 20 & 16820 & 0.63674 \\
\hline 7 & 1276 & 6.3946 & 21 & 13080 & 0.81695 \\
\hline 8 & 829 & 1.2435 & 22 & 9560 & 0.54254 \\
\hline 9 & 17950 & 0.42756 & 23 & 33090 & 0.2633 \\
\hline 10 & 8716 & 0.79645 & 24 & 36460 & 0.71416 \\
\hline 11 & 9838 & 0.77593 & 25 & 11070 & 0.81544 \\
\hline 12 & 12110 & 0.77887 & 26 & 23180 & 0.84997 \\
\hline 13 & 6259 & 1.9819 & 27 & 7352 & 0.5514 \\
\hline 14 & 12590 & 0.45068 & & & \\
\cline { 1 - 3 }
\end{tabular}




\section{Grey analysis}

The results of the EIS tests are given in Table 4. The further transformation of the results based on the grey relational analysis is given in Table 5.

\section{Normalisation of the experimental results}

The first step of the grey relational analysis is to perform the linear normalization of the experimental results $\left(R_{\mathrm{ct}}\right.$ and $\left.C_{\mathrm{dl}}\right)$ in the range between 0 and 1 . This is known as grey relational generating. The normalization can be done based on three objectives which include (1) normalization by maximum value (lower-thebetter), (2) normalization by minimum value (higher-the-better) and (3) normalization by objective value. The present study aims to maximize the corrosion resistance of Ni-B coatings. Since, a higher $R_{\mathrm{ct}}$ value and a lower $C_{\mathrm{dl}}$ value indicate higher corrosion resistance; normalization of the former is carried out with higher the better criterion, while the latter with lower the better criterion. The normalization expressions for both are given as follows:

$$
\begin{aligned}
& x_{i}(k)=\frac{y_{i}(k)-\min y_{i}(k)}{\max y_{i}(k)-\min y_{i}(k)} \quad ; \text { (higher-the-better) } \\
& x_{i}(k)=\frac{\max y_{i}(k)-y_{i}(k)}{\max y_{i}(k)-\min y_{i}(k)} \quad ;(\text { lower-the better) }
\end{aligned}
$$

where $x_{i}(k)$ is the value after grey relational generation, while $\min y_{i}(k)$ and $\max y_{i}(k)$ are respectively, the smallest and largest values of $y_{i}(k)$ for the $k$ th response; $k$ being $1\left(R_{\mathrm{ct}}\right)$ and $2\left(C_{d l}\right)$. The processed data after grey relational generation are given in Table 5. Larger normalized results correspond to the better performance and the best normalized result should be equal to 1 .

\section{Computation of grey relational coefficients}

Grey relational coefficients are calculated to express the relationship between the ideal (best $=1$ ) and the actual experimental results. The Grey relational coefficient $\xi_{i}(k)$ can be calculated as:

$$
\xi_{i}(k)=\frac{\Delta_{\min }+\psi \Delta_{\max }}{\Delta_{0 i}(k)+\psi \Delta_{\max }}
$$

where $\Delta_{0 i}=\left\|x_{0}(k)-x_{i}(k)\right\|=$ difference of the absolute value between $x_{0}(k)$ and $x_{i}(k), \Delta_{\min }$ and $\Delta_{\max }$ are respectively the minimum and maximum values of the absolute differences $\left(\Delta_{0 i}\right)$ of all comparing sequences, and $\Psi$ is the distinguishing coefficient which is defined in the range $0 \leq \Psi \leq 1$. The distinguishing coefficient weakens the effect of $\Delta_{\max }$ when it gets too big, enlarging the different significance of the relational coefficient. The values of $\Delta_{0 i}$ and grey relational coefficients (with $\Psi=0.5$ ) are given in Table 5. 
Table 5. Grey relational analysis for $R_{\mathrm{ct}}$ and $C_{\mathrm{dl}}$.

\begin{tabular}{|c|c|c|c|c|c|c|}
\hline \multirow{2}{*}{ Exp. No. } & \multicolumn{2}{|c|}{ Normalized data } & \multicolumn{2}{c|}{ Values of $\Delta_{0 \mathrm{i}}$} & \multicolumn{2}{c|}{ Grey relational coefficient } \\
\cline { 2 - 7 } & $R_{\mathrm{ct}}$ & $C_{\mathrm{dl}}$ & $R_{\mathrm{ct}}$ & $C_{\mathrm{dl}}$ & $R_{\mathrm{ct}}$ & $C_{\mathrm{dl}}$ \\
\hline 1 & 0.0403 & 0.6512 & 0.9596 & 0.3487 & 0.3425 & 0.5891 \\
\hline 2 & 0.0382 & 0.8908 & 0.9617 & 0.1091 & 0.3420 & 0.8208 \\
\hline 3 & 0.0125 & 0.3810 & 0.9874 & 0.6189 & 0.3361 & 0.4468 \\
\hline 4 & 0.0000 & 0.4303 & 1.0000 & 0.5696 & 0.3333 & 0.4674 \\
\hline 5 & 0.2277 & 0.9238 & 0.7722 & 0.0761 & 0.3930 & 0.8678 \\
\hline 6 & 0.0093 & 0.8303 & 0.9907 & 0.1696 & 0.3354 & 0.7466 \\
\hline 7 & 0.0138 & 0.0000 & 0.9861 & 1.0000 & 0.3364 & 0.3333 \\
\hline 8 & 0.0013 & 0.8401 & 0.9986 & 0.1598 & 0.3336 & 0.7577 \\
\hline 9 & 0.4811 & 0.9732 & 0.5188 & 0.0267 & 0.4907 & 0.9491 \\
\hline 10 & 0.2223 & 0.9130 & 0.7776 & 0.0869 & 0.3913 & 0.8518 \\
\hline 11 & 0.2538 & 0.9163 & 0.7461 & 0.0836 & 0.4012 & 0.8567 \\
\hline 12 & 0.3175 & 0.9159 & 0.6824 & 0.0840 & 0.4228 & 0.8560 \\
\hline 13 & 0.1535 & 0.7197 & 0.8464 & 0.2802 & 0.3713 & 0.6407 \\
\hline 14 & 0.3309 & 0.9694 & 0.6690 & 0.0305 & 0.4277 & 0.9423 \\
\hline 15 & 0.0811 & 0.9175 & 0.9188 & 0.0824 & 0.3523 & 0.8584 \\
\hline 16 & 0.0802 & 0.9461 & 0.9197 & 0.0538 & 0.3521 & 0.9028 \\
\hline 17 & 0.1669 & 0.9315 & 0.8330 & 0.0684 & 0.3750 & 0.8795 \\
\hline 18 & 0.4820 & 0.9452 & 0.5179 & 0.0547 & 0.4911 & 0.9013 \\
\hline 19 & 0.2572 & 0.7954 & 0.7427 & 0.2045 & 0.4023 & 0.7096 \\
\hline 20 & 0.4495 & 0.9390 & 0.5504 & 0.0609 & 0.4759 & 0.8914 \\
\hline 21 & 0.3446 & 0.9097 & 0.6553 & 0.0902 & 0.4327 & 0.8470 \\
\hline 22 & 0.2460 & 0.9544 & 0.7539 & 0.0455 & 0.3987 & 0.9165 \\
\hline 23 & 0.9055 & 1.0000 & 0.0944 & 0.0000 & 0.8411 & 1.0000 \\
\hline 24 & 1.0000 & 0.9264 & 0.0000 & 0.0735 & 1.0000 & 0.8717 \\
\hline 25 & 0.2883 & 0.9099 & 0.7116 & 0.0900 & 0.4126 & 0.8473 \\
\hline 26 & 0.6277 & 0.9043 & 0.3722 & 0.0956 & 0.5732 & 0.8393 \\
\hline 27 & 0.1841 & 0.9530 & 0.8158 & 0.0469 & 0.3799 & 0.9140 \\
\hline & & & & & & \\
\hline
\end{tabular}

Table 6. Grey relational grade and order.

\begin{tabular}{|c|c|c|c|c|c|}
\hline Exp. No. & Grey relational grade & Order & Exp. No. & Grey relational grade & Order \\
\hline 1 & 0.4658 & 24 & 15 & 0.6054 & 18 \\
\hline 2 & 0.5814 & 19 & 16 & 0.6275 & 15 \\
\hline 3 & 0.3914 & 26 & 17 & 0.6273 & 16 \\
\hline 4 & 0.4003 & 25 & 18 & 0.6962 & 5 \\
\hline 5 & 0.6304 & 12 & 19 & 0.5560 & 20 \\
\hline 6 & 0.5410 & 22 & 20 & 0.6836 & 7 \\
\hline 7 & 0.3348 & 27 & 21 & 0.6399 & 10 \\
\hline 8 & 0.5456 & 21 & 22 & 0.6576 & 8 \\
\hline 9 & 0.7199 & 3 & 23 & 0.9205 & 2 \\
\hline 10 & 0.6216 & 17 & 24 & 0.9358 & 1 \\
\hline 11 & 0.6289 & 14 & 25 & 0.6300 & 13 \\
\hline 12 & 0.6394 & 11 & 26 & 0.7063 & 4 \\
\hline 13 & 0.5060 & 23 & 27 & 0.6470 & 9 \\
\hline 14 & 0.6850 & 6 & & &
\end{tabular}


Table 7. Mean table for grey relational grade.

\begin{tabular}{|l|c|c|c|c|}
\hline Level & A & B & C & D \\
\hline 1 & 0.5123 & 0.5787 & 0.5333 & 0.6103 \\
\hline 2 & 0.6264 & 0.6536 & 0.6677 & 0.6385 \\
\hline 3 & 0.7086 & 0.6150 & 0.6463 & 0.5985 \\
\hline Delta & 0.1962 & 0.0749 & 0.1344 & 0.0400 \\
\hline Rank & 1 & 3 & 2 & 4 \\
\hline \multicolumn{5}{|c|}{ Men grey relational grade $=0.6157$}
\end{tabular}

\section{Computation of grey relational grade}

The Grey relational coefficient of each performance characteristic is to be computed and the overall evaluation of the multi response characteristics is based on the Grey relational grade, which is given by:

$\alpha_{i}=\frac{1}{n} \sum_{k=1}^{n} \xi_{i}(k)$

where $n=$ number of performance characteristics ( 2 in present case). The results of the Grey relational grade are produced in Table 6. Higher Grey relational grade represents that the experimental result is closer to the ideally normalized value. Thus, the higher the grey relational grade, the closer the corresponding parameter combination to the optimal.

\section{Analysis of signal to noise ratio}

To evaluate robustness, Taguchi method needs to capture the variability within a trial condition. The said purpose is fulfilled by employing the $\mathrm{S} / \mathrm{N}$ ratio approach to measure the quality characteristic deviating from the desired value for the evaluation characteristic in the optimum parameter analysis. In the present work $\mathrm{S} / \mathrm{N}$ ratio analysis is done with grey relational grade as the performance index. Since, grey relational grade is to be maximized, the $\mathrm{S} / \mathrm{N}$ ratio is calculated using higher the better criterion which is given by:

$\mathrm{S} / \mathrm{N}=-10 \log \left(\frac{1}{n} \sum \frac{1}{y^{2}}\right)$

where $y$ is the observed data and $n$ is the number of observations. The columns of the OA are orthogonal to each other. Hence it is possible to extract the effect of each process parameter at different levels. The average of the grey relational grade ratio for each level of the factors of A, B, C and D is given in Table 7. The table also consists of ranks based on Delta values. The Delta value corresponding to a parameter is nothing but the difference of the highest and the lowest mean grey grade of the levels. The parameter with the highest Delta value is assigned rank 1, while the parameter with the lowest value is ranked the last one. All the other parameters are ranked according to their Delta values. The parameter possessing higher Delta value has greater influence over the response. From Table 7, it is found that parameter A, i.e., bath temperature, possesses the highest 
Delta value and hence has the greatest influence over the corrosion of electroless Ni-B coatings.

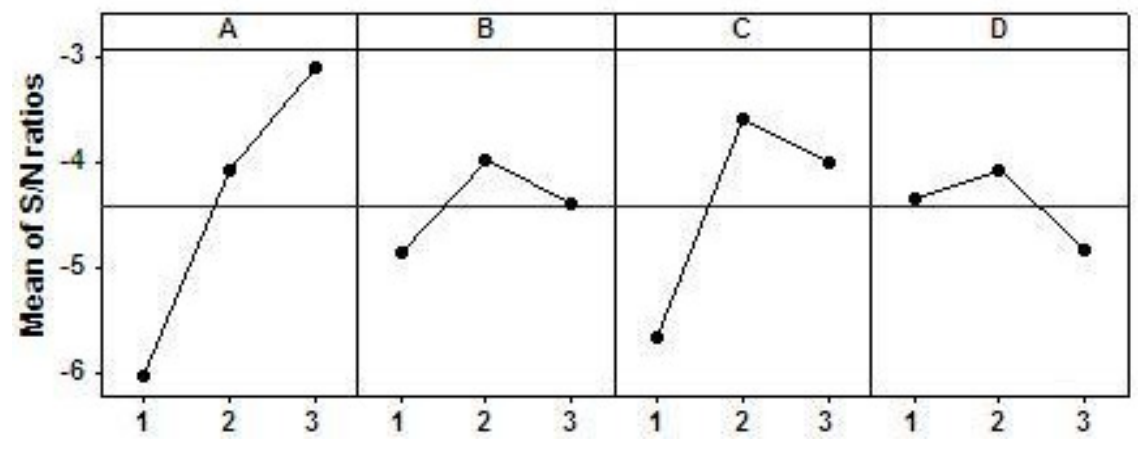

Figure 5. Main effects plot.

The main effect and interaction effect plots are illustrated in Fig. 5 and Fig. 6, respectively. The main effects plot gives the optimal combination of coating parameters for minimum corrosion. Since, Taguchi method obtains the optimal level combination by choosing those levels for which $\mathrm{S} / \mathrm{N}$ ratio is the highest; the optimal combination of parameters is found to be A3B2C2D2. Moreover, the main effect plot gives a rough idea about the relative significance of the process parameters on the system response. This is determined by the slope of the main effect plot for each parameter. The plot having higher inclination will have higher influence. From Fig. 5, it is clear that factor A, i.e., bath temperature, is the most significant factor, while factor $\mathrm{C}$ is also quite significant. The remaining factors are moderately significant. In case of interaction plots non-parallelism of the parameter plots is observed. Non-parallel lines are indicative of the presence of interaction, while intersecting lines are indicative of the presence of strong interaction.

From the interaction plots (Fig. 6), it can be observed that quite strong interaction exists between all the factors, e.g., between factors A and B and between B and C. In this respect it can be noted that the ratio of optimal level of borohydride (B2) and that of nickel chloride (C2) may be helping in achieving a defect free coating surface with better passivity ability that reduces the probability of the formation of localized corrosion cells. Moreover, the porosity in the coatings is found to decrease as the superficial roughness diminishes and the thickness of the film increases [13]. Generally, a small area ratio between the substrate and the coating causes a rapid corrosion of the substrate and the destruction of the coated system. A highly porous coating prevents the anodic current density from reaching the critical passivity current density. If the porosity is lesser, the corrosion resistivity of the coated material is better. Now, bath temperature is responsible for the mobility of the ions in the solution and hence it is found to control the thickness of electroless coatings by speeding up the reactions. As it can be seen that the thickness of the coating affects its corrosion characteristics, bath temperature playing a significant role on the corrosion behavior may roughly be explained. Also higher bath temperature (A3) generally results in a 
thicker deposition, which again results in improved corrosion resistivity of the coating.

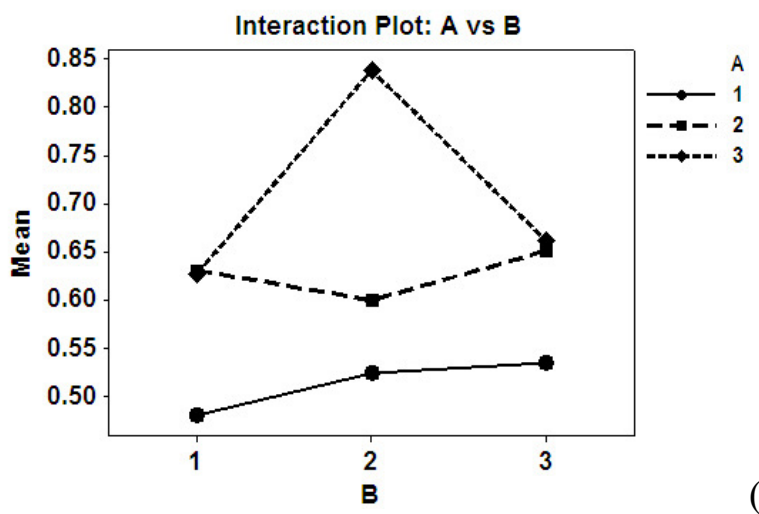

(a)

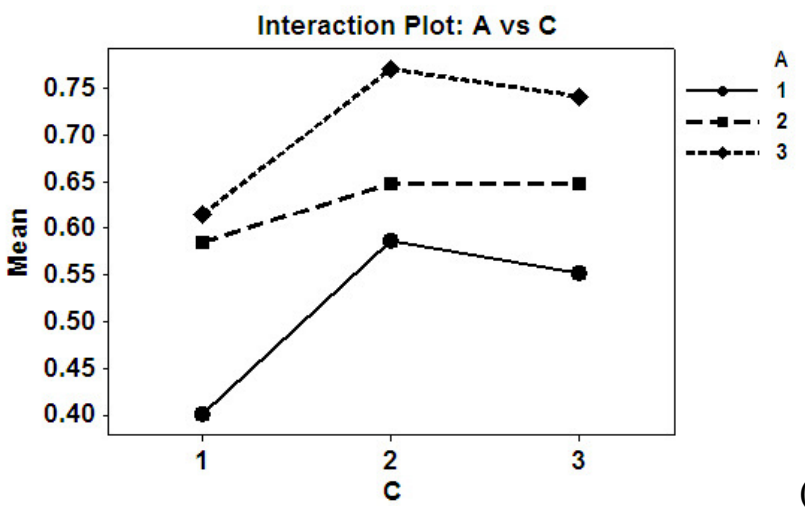

(b)

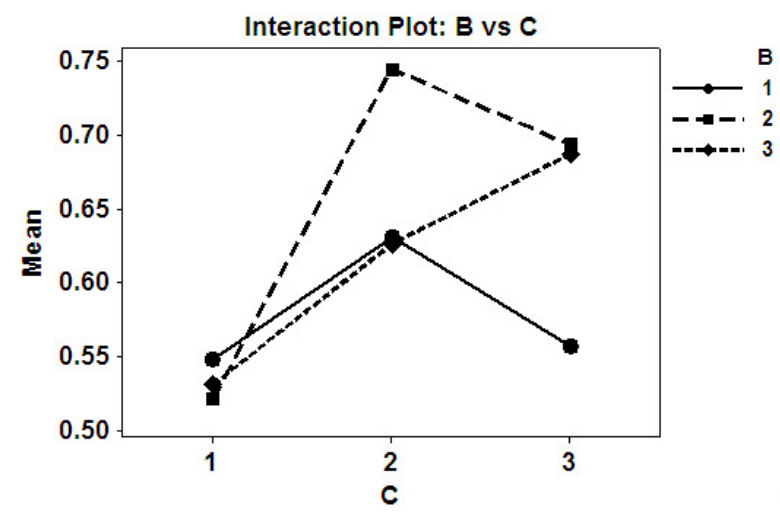

(c)

Figure 6. Plots of interaction effects for mean grey grade (a) A vs. B, (b) A vs. C and (c) B vs. C

\section{Analysis of variance}

ANOVA is a statistical technique to find out the significance of individual process parameters and their interactions on the system response under consideration and also their respective percentages of contribution. This is done by separating the total variability of the response used, which is measured by the sum of the squared deviations from the total mean response, into contributions by each of the design parameters and the error. In the present study ANOVA is performed using Minitab [21]. ANOVA results for corrosion of electroless Ni-B 
coating is shown in Table 8. In ANOVA, a ratio called F-ratio, which is the ratio between the regression mean square and mean square error is used to measure the significance of the parameters under investigation with respect to the variance of all the terms included in the error term at the desired significance level, $\alpha$. A calculated F-ratio which is higher than the tabulated F-ratio indicates that the factor is significant at desired $\alpha$ level. ANOVA table also shows the percentage contribution of each parameter. It is seen that parameter A, i.e. bath temperature, has got the most significant influence on corrosion at the confidence level of $99 \%$. Parameter C, i.e. concentration of nickel source, also plays significant (95\% confidence level) role in controlling the corrosion behavior of electroless $\mathrm{Ni}$-B coating within the specific test range. No other parameter is significant at the said level of confidence. Among interactions, interaction $\mathrm{A} \times \mathrm{B}$ is found to be significant at $75 \%$ confidence level with a contribution of $13 \%$, while interaction $\mathrm{B} \times \mathrm{C}$ is found to have a contribution of about $9 \%$ in influencing the corrosion behavior of the coating.

Table 8. Results of ANOVA.

\begin{tabular}{|c|c|c|c|c|c|}
\hline Source & DF & SS & MS & F & \% contribution \\
\hline A & 2 & 0.174780 & 0.087390 & $11.40^{\mathrm{b}}$ & 37.95 \\
\hline B & 2 & 0.025248 & 0.012624 & 1.65 & 5.48 \\
\hline C & 2 & 0.093829 & 0.046914 & $6.12^{\mathrm{c}}$ & 20.37 \\
\hline $\mathrm{D}$ & 2 & 0.007614 & 0.003807 & 0.50 & 1.65 \\
\hline $\mathrm{A} \times \mathrm{B}$ & 4 & 0.060977 & 0.015244 & $1.99^{\mathrm{d}}$ & 13.24 \\
\hline $\mathrm{A} \times \mathrm{C}$ & 4 & 0.013177 & 0.003294 & 0.43 & 2.86 \\
\hline $\mathrm{B} \times \mathrm{C}$ & 4 & 0.038944 & 0.009736 & 1.27 & 8.45 \\
\hline Error & 6 & 0.045975 & 0.007662 & & \\
\hline Total & 26 & 0.460543 & & & \\
\hline
\end{tabular}
bignificant at 99\% confidence level $\left(\mathrm{F}_{0.01,2,6}=10.9\right) ;{ }^{\text {c }}$ Significant at $95 \%$ confidence level $\left(\mathrm{F}_{0.05,2,6}=\right.$
5.14); ${ }^{\mathrm{d}}$ Significant at $75 \%$ confidence level $\left(\mathrm{F}_{0.25,4,6}=1.79\right)$

\section{Validation experiment}

A validation test is the final step of the design of experiment problem, in which the improvement in the response obtained at the optimal combination of the parameters is compared to that at the initial condition. Estimated grey relational grade $(\hat{\gamma})$ is calculated at the optimal condition with the help of the following expression:

$$
\hat{\gamma}=\gamma_{m}+\sum_{i=1}^{o}\left(\bar{\gamma}_{i}-\gamma_{m}\right)
$$

where $\gamma_{m}$ is the total mean grey relational grade, $\overline{\gamma_{i}}$ is the mean grey relational grade at the optimal level, and $o$ is the number of the main design parameters that significantly affect the polarization characteristics of electroless $\mathrm{Ni}-\mathrm{B}$ coating. The comparison of the predicted grey relational grade, experimental grey relational grade and the grey relational grade at the initial condition is shown in Table 9. The mid-level combination of coating parameters is assumed as the 
initial condition. From the table, it is found that the improvement of grey relational grade at the optimal condition is 0.3239 , which is about $53 \%$ of the mean grey relational grade. This is considered to be a significant improvement. The impedance plots for coatings developed with initial and optimal combination of parameters are shown in Figure 7. Moreover, the plot of the initial coating in as deposited phase is also included in the figure. It can be seen that the plots exhibit a semicircular nature in the higher frequency region but the semicircles have different sizes. This indicates that the same corrosion phenomenon is occurring but over a larger area. Although some researchers have found that heat treatment decreases the corrosion resistance of the coating, somewhat contradictory observations are noticed in the present study. The improved corrosion resistance of the heat treated coating over as deposited one may be attributed to improvement in the coating density, structure and morphology as observed by other researchers [5].

Table 9. Results of confirmation test.

\begin{tabular}{|c|c|c|c|}
\hline \multirow{2}{*}{} & \multirow{2}{*}{ Initial parameter } & \multicolumn{2}{|c|}{ Optimal parameter } \\
\cline { 3 - 4 } & & Prediction & Experimental \\
\hline Level & $\mathrm{A} 2 \mathrm{~B} 2 \mathrm{C} 2 \mathrm{D} 2$ & \multicolumn{2}{|c|}{$\mathrm{A} 3 \mathrm{~B} 2 \mathrm{C} 2 \mathrm{D} 2$} \\
\hline$R_{\mathrm{ct}}\left(\mathrm{ohms} / \mathrm{cm}^{2}\right)$ & 5080 & & 33090 \\
\hline$C_{\mathrm{dl}}\left((\mathrm{F}) \times 10^{-4}\right)$ & 0.8786 & & 0.2633 \\
\hline Grade & 0.5966 & 0.7390 & 0.9205 \\
\hline
\end{tabular}

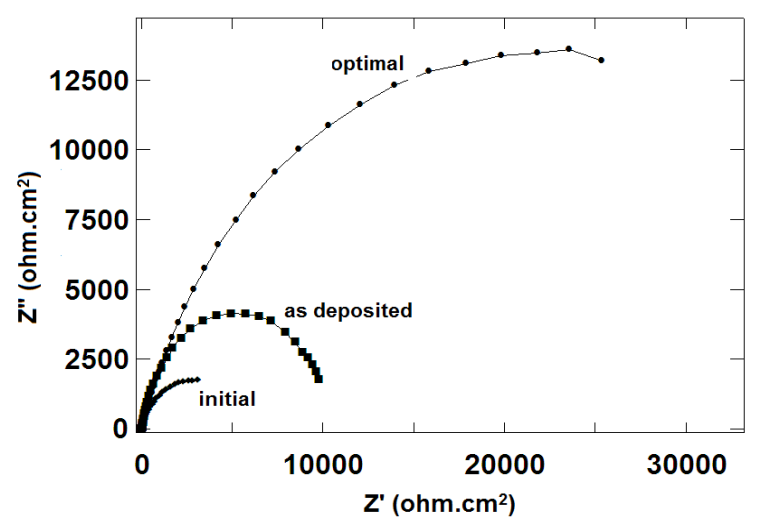

Figure 7. Impedance plots: as deposited, initial and optimal.

\section{Conclusion}

In this study Taguchi method, in combination with Grey relational analysis, is successfully applied in order to optimize the electrochemical characteristics of electroless Ni-B coating via electrochemical impedance spectroscopy. $L_{27}$ orthogonal array is employed for the optimization process and the optimum parameter combination for maximum corrosion protection is found to be A3B2C2D2 (Highest level of bath temperature, Middle level of reducing agent 
concentration, Middle level of nickel source concentration, Middle level of annealing temperature). Bath temperature and concentration of nickel source is found to be the main contributors in controlling the corrosion resistance of the coating. The improvement in the Grey relational grade compared to the mean grade is about 53\%. The surface of electroless Ni-B coating is found to be nodular in nature resembling that of a cauliflower surface. Moreover, the coating is found to be amorphous in as deposited phase but gradually turn crystalline with heat treatment.

\section{Acknowledgements}

First author gratefully acknowledges the research support provided by Council of Scientific and Industrial Research, India: File No. 9/96(0621)2K10-EMR-I dated 05/03/2010.

\section{References}

1. G.O. Mallory, J.B. Hadju, Electroless Plating: Fundamentals and Applications, Orlando: AESF; 1991.

2. W. Riedel, Electroless Nickel Plating, Ohio: ASM International; 1991.

3. P. Sahoo, S.K. Das, Mater. Des. 32 (2010) 1760-1775.

4. P. Sahoo, S.K. Pal, Tribol. Lett. 28 (2007).191-201.

5. $\quad$ F. Bigdeli, S.R. Allahkaram, Mater. Des. 30 (2009) 4450-4453.

6. T.S.N.S. Narayanan, K. Krishnaveni, S.K. Seshadri, Mater. Chem. Phys. 82 (2003) 771-779.

7. A.F. Kanta, V. Vitry, F. Delaunois, J. Alloys Compd. 486 (2009) L21-L23.

8. F. Delaunois, P. Lienard, Surf. Coat. Technol.160 (2002) 239-248.

9. K.N. Srinivasan, R. Meenakshi, A. Santhi, P.R. Thangavelu, S. John, Surf. Eng. 26 (2010) 153-158.

10. T.S.N.S. Narayanan, S.K. Seshadri, J. Alloys. Compd. 365 (2004) 197-205.

11. C.T. Dervos, J. Novakovic, P. Vassiliou, Mater Lett. 58 (2004) 619-623.

12. M. Anik, E. Körpe, E. Şen, Surf. Coat. Technol. 202 (2008) 1718-1727.

13. I. Baskaran, T.S.N.S. Narayanan, A. Stephen, Trans. Inst. Met. Finish 87 (2009) 221-224.

14. A. Contreras, C. León, O. Jimenez, E. Sosa, R. Pérez, Appl. Surf. Sci. 253 (2006) 592-599.

15. R.K. Roy, A primer on the Taguchi method. Dearborn, Michigan: Society of Manufacturing Engineers; 1990.

16. G. Taguchi, Introduction to Quality Engineering. Asian Productivity Organization; 1990.

17. P.J. Ross, Taguchi Techniques for Quality Engineering. 2nd edn., New York: McGraw Hill; 1996.

18. J. Deng, J. Grey System 1 (1989) 1-24.

19. K.M. Gorbunova, M.V. Ivanov, V.P. Moiseev, J. Electrochem. Soc. 120 (1973) 613-618. 
20. W.J. Cheong, B.L. Luan, D.W. Shoesmith, Corros. Sci. 49 (2007) 17771798.

21. Minitab User Manual. Making data analysis easier. 13.2 edn. State College, PA, USA: MINITAB Inc.; 2001. 